\title{
The significance of miR-145 in the prediction of preeclampsia
}

\author{
Han L, Zhao Y, Luo QQ, Liu XX, Lu SS, Zou L \\ Obstetrics and Gynecology, Union Hospital, Tongji Medical College, Huazhong University \\ of Science and Technology, Wuhan, China. zouli2017@163.com
}

\section{ABSTRACT}

AIM: The aim of this study was to explain the effects of miRNA-145 in the pathogenesis of preeclampsia. METHODS: Collecting the placental tissue of 40 severe preeclampsia patients and 20 normal pregnant women, and observation of the pathological findings by HE staining. Measuring the miR-145 by RT-PCR. EVCT were divided into NC group; MC group and miRNA group. The EVCT cells of MC and miRNA groups were simulated by hypoxia in vivo by $\mathrm{CoCl}_{2}$. Measuring the proliferation rate of different groups by MTT testing. The cells apoptosis rates were measured by flow cytometry; evaluating PI3K, Akt, mTOR and P53 gene and protein expression of three groups by RT-PCR and WB.

RESULTS: Compared to the normal pregnant placental tissue. The miR-145 expression of preeclampsia pregnant placental tissue was significantly decreased $(p<0.05)$. In the cell experiments, the proliferation rate was significantly increased, and the cell apoptosis rate was significantly reduced in MC group compared to the MC group ( $p<0.05$, respectively). Comparing with MC group, the PI3K, Akt and mTOR gene and protein expression of miRNA group were significantly up-regulated and the P53 expression was significantly down-regulated ( $p<0.05$, respectively).

CONCLUSION: miR-145 might have effects to predict preeclampsia via PI3K/Akt/mTOR signalling pathways (Fig. 5, Ref. 30). Text in PDF www.elis.sk.

KEY WORDS: preeclampsia, EVCT, MiR-145, PI3K/Akt/mTOR, P53.

\section{Introduction}

Preeclampsia is a disease in the late pregnancy, the disease originate in placenta and is a serious threat to the maternal and child health, placenta plays an important role in the pathogenesis of the disease (1). Nap outside nourish cells has played a key role in placenta formation and in a successful pregnancy to ensure the oxygen and nutrients exchange between foetus and mother, which has a vital significance (2). So far, the pathogenesis of preeclampsia was not clearly explained, but more recognized cause of hypothesis is increased apoptosis of Sertoli cell, leading to insufficient placental blood supply $(3-6)$.

MicroRNAs are a class of about $21 \sim 26$ bases, which widely exist in animals and plants of non-coding single small RNAs that are highly conservative, stable and evolution after the gene transcription level functions to regulate cell growth, and has an extremely important pathological and physiological significance (7). Related researches confirmed that there was a close correlation between miRNA and cell apoptosis and proliferation $(8-11)$. In this study, we detected miRNA-145 expression in normal maternal and preeclampsia women, and explored miRNA-145's effects in the mechanism of the preeclampsia.

Obstetrics and Gynecology, Union Hospital, Tongji Medical College, Huazhong University of Science and Technology, Wuhan, China

Address for correspondence: L. Zou, Obstetrics and Gynecology, Union Hospital, Tongii Medical College, Huazhong University of Science and Technology, Wuhan 430022, China.

\section{Materials and methods}

\section{Study objects}

Selecting 40 patients that were pregnant with severe preeclampsia from 2012.10 to 2015.9 treated in our hospital, the average age was $(30.25 \pm 5.16)$ years, the average gestational age was $(37.15 \pm 1.65)$ weeks. Selecting 20 pregnant women with normal late pregnancy as the control group in the same period, the average age was $(29.74 \pm 4.16)$ years, the average gestational age was $(37.86 \pm 1.32)$ weeks. There were no significant differences between the two pregnant women groups in age and gestational age $(p>0.05$, respectively). Pregnant women included in this study had no history of smoking, blood transfusion, and immunotherapy, were singletons and other obstetric complications were ruled out. After caesarean section, the placenta tissue from the normal group, mild preeclampsia group and severe preeclampsia group was fully rinsed, fixed to $10 \%$ Formaldehyde Solution, paraffin embedded, serial sections, HE stained to observe the histological characteristics of placenta and measuring the miRNA-145 expression in difference tissues.

\section{Materials}

Primitive culture EVCT; DMEM/F12 (U.S, Hyclone company); Trypsin, BSA, DAPI (U.S, Sigma company); SYBR Green qPCR Maser Mix (Japan, Toyobo company); rabbit anti human PI3K, Akt, mTOR and P53 (U.S, Abcam company); Primer and miRNA-145 (Shanghai biological engineering co.,LTD) 
$523-528$

\section{Cell culture}

EVCT cells were divided into the three groups: NC group, MC group and miRNA group. NC group were cultured with DMEM/ F12; MC group were using $\mathrm{CoCl}_{2}$ chemical hypoxia induced cell hypoxia; miRNA group were based on MC group adding miRNA-145 transfection.

\section{MTT Detection}

We used MTT (Sigma, USA) manual kit following by instructions to determine the cell survival rate.

\section{Cell apoptosis testing}

Cells inoculated in six orifice by $5 \times 10^{4}$ density, culturing the cells in DMEM/F12 contained $10 \%$ foetal bovine serum, until cell fusion achieved $50.0 \% \sim 60.0 \%$. The cells were treated by different methods, collecting cell to the EP tube after pancreatic enzyme digestion, washing cells twice by PBS, centrifugal as $10000 \mathrm{r} / \mathrm{min}$ for $5 \mathrm{~min}$, measuring the cell apoptosis of difference groups.
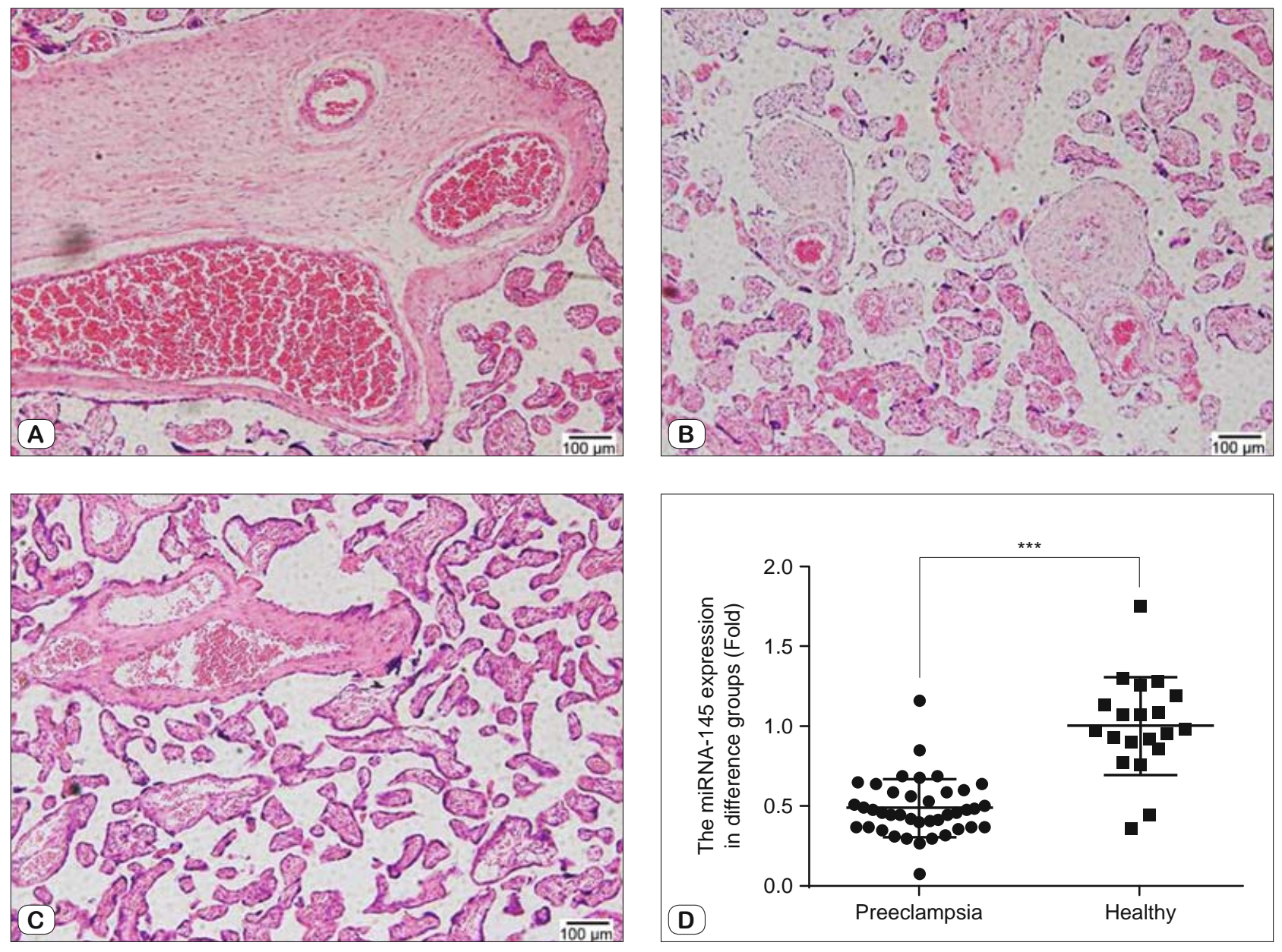

Fig. 1. The clinical data in difference tissues. A) The Placental tissue of Normal puerperal. B) The Placental tissue of Mild preeclampsia. C) The Placental tissue of severe preeclampsia. D) The miRNA-145 expression of difference tissues. ***: $\mathbf{p}<0.05$, Compared with Healthy puerperal. 
WB assay

Total proteins were extracted from the cells of all groups. Protein concentrations were determinate by BCA. The sample was separated by 50 SDS-PAGE with a concentration of $12 \% \mathrm{~g}$, which was transferred to the membrane. The membrane was closed and added to the assay for the night. Washing the membrane, adding two anti, staining in room temperature incubation $1 \mathrm{~h}$, with TBST after washing the membrane.

\section{Statistical analysis}

All data were expressed by the mean $\pm \mathrm{SD}(\bar{x} \pm s)$, All data were used and included in SPSS19.0 (SPSS Inc., Chicago, USA) statistical package for statistical analysis. Using ANOVA and LSD analysis was used to analyse all the data, $\mathrm{p}<0.05$ showed that the difference was statically significant.

\section{Results}

\section{Clinical data}

The trophoblast cells in normal term placental villi and mild pre- eclampsia placental villi were mainly trophoblastic cells
(Figs 1A, 1B). In severe preeclampsia placenta, trophoblast cell proliferation, basement membrane thickening of trophoblastic cells, villous interstitial fibrin deposition, syncytiotrophoblast nodules increased, syncytiotrophoblast budding, fibrinoid necrosis of villi increased, villous vessels increased, villi part of not mature decidual stromal cells showed a different size block, rhabditiform, decidual vascular endothelial cell fibrosis, decidual fibrinoid necrosis was also increased significantly (Fig. 1C). Compared to the healthy pregnant women, the miR-145 expression of preeclampsia women was significantly reduced $(\mathrm{p}<0.05)$, the data are shown in Figure 1D.

\section{MTT testing}

The cell proliferation rate of miRNA group was significantly increased compared to that of MC group $(\mathrm{p}<0.05)$, the data are shown in Figure 2.

\section{Cell apoptosis}

The cell apoptosis rate of miRNA group was significantly reduced compared to that of $\mathrm{MC}$ group $(\mathrm{P}<0.05)$, the data are shown in Figure 3.
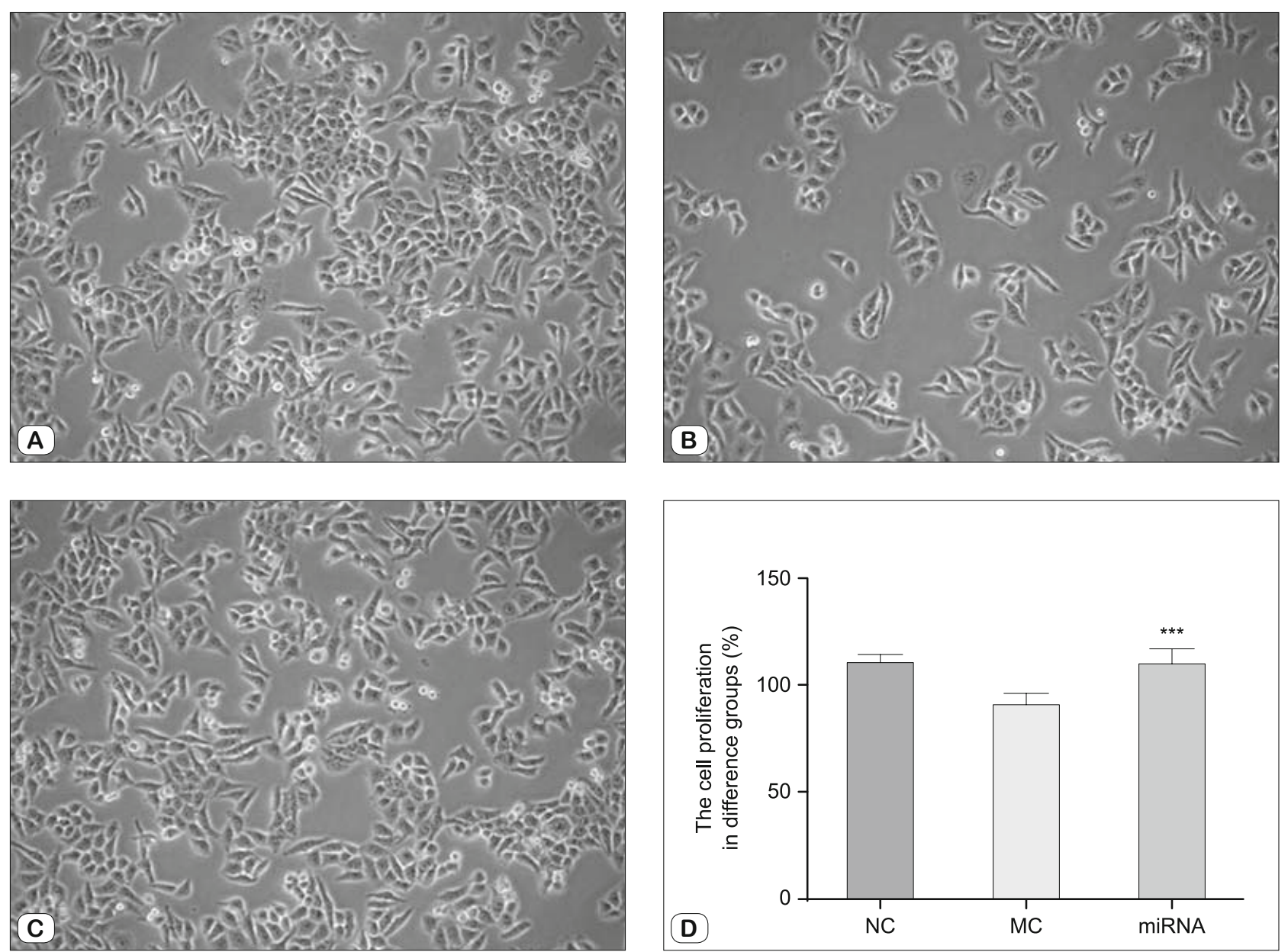

Fig. 2. The proliferation rate of difference groups. A) The proliferation cells of NC group. B) The proliferation cells of MC group. C) The proliferation cells of miRNA group. D) Comparing the proliferation rate of difference groups. $* * *: p<0.05$, Compared with MC group. 

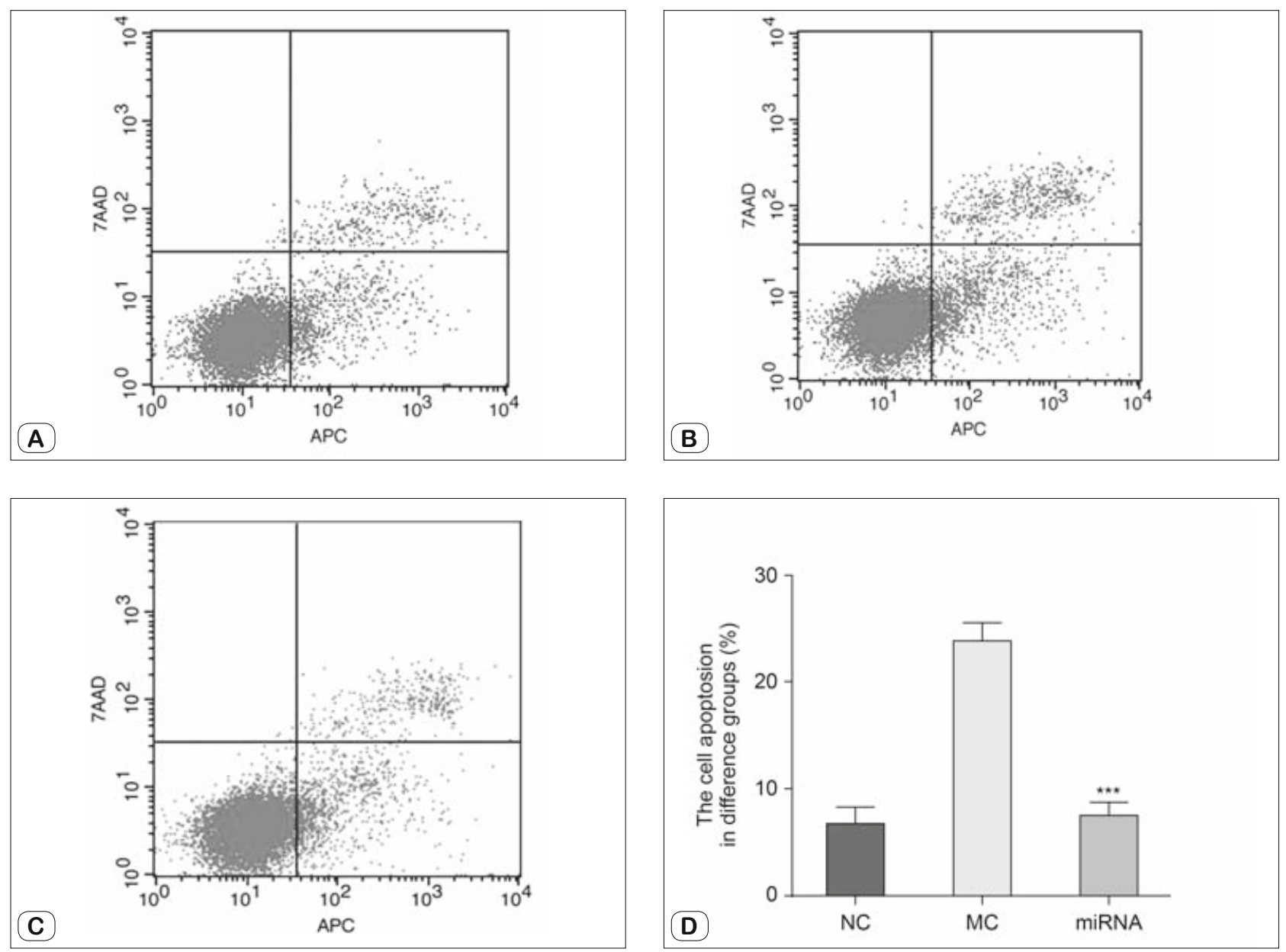

Fig. 3. The cell apoptosis rate of difference groups. A) The apoptosis rate of NC group. B) The apoptosis rate of MC group. C) The apoptosis rate of miRNA group. D) Comparing the apoptosis rate of difference groups. ***: $p<0.05$, Compared with MC group.

\section{RT-PCR}

Comparing to the MC group, the PI3K, Akt and mTOR gene expression of miRNA group were significantly up-regulated, however, the P53 gene expression of miRNA group was significantly downregulated ( $(p<0.05$, respectively). The data are shown in Figure 4.

\section{WB testing}

Comparing to the MC group, the PI3K, Akt and mTOR protein expression of miRNA group were significantly up-regulated, however, the $\mathrm{P} 53$ protein expression of miRNA group was significantly downregulated ( $p<0.05$, respectively). The data are shown in Figure 5.

\section{Discussion}

In normal pregnancy, Sertoli cell apoptosis with the growth of the placenta and the extension of gestational age. However, in preeclampsia, abnormal cellular renewal is present. Placental villi Sertoli cell apoptosis increases. Preeclampsia placenta lesion features include: fuzzy morphological changes, cell apoptosis and fit nodules fall off; these changes and the imbalance of oxygen and inflammatory factors have a close correlation (12-16). Apoptosis in preeclampsia and placental pathologic changes of the specific mechanism remains to be studied. Numerous studies confirmed that the miRNA-145 could effectively regulate the proliferation and apoptosis of tumour cells (17-20), however, the role of miRNA-145 in preeclampsia is still limited. This study was aimed to evaluate miRNA-145 in preeclampsia function and mechanism.

$\mathrm{PI} 3 \mathrm{~K} / \mathrm{Akt} / \mathrm{mTOR}$ signalling pathways is one of the important ways of the cell membrane receptor signal transduction, such as cell growth, proliferation, metabolism, apoptosis plays an important role in this process (21). PI3K can regulate AKT activation, phosphorylated AKT activation or inhibit further downstream target proteins, involved in cell proliferation, migration, survival and metabolism and other physiological activities (22). AKT as the central part of the pathway, in charge of by PI3K initiating biological information transmission, can be applied to the downstream of the mTOR targets $(23,24)$. Related studies confirmed the activation of mTOR and there was a close correlation between P53 gene expression (25-27). And studies have shown that excessive P53 expression could promote cell apoptosis (28-30).

In this study, we found that miRNA-145 gene expression of preeclampsia patient's placenta tissue was significantly lower than 

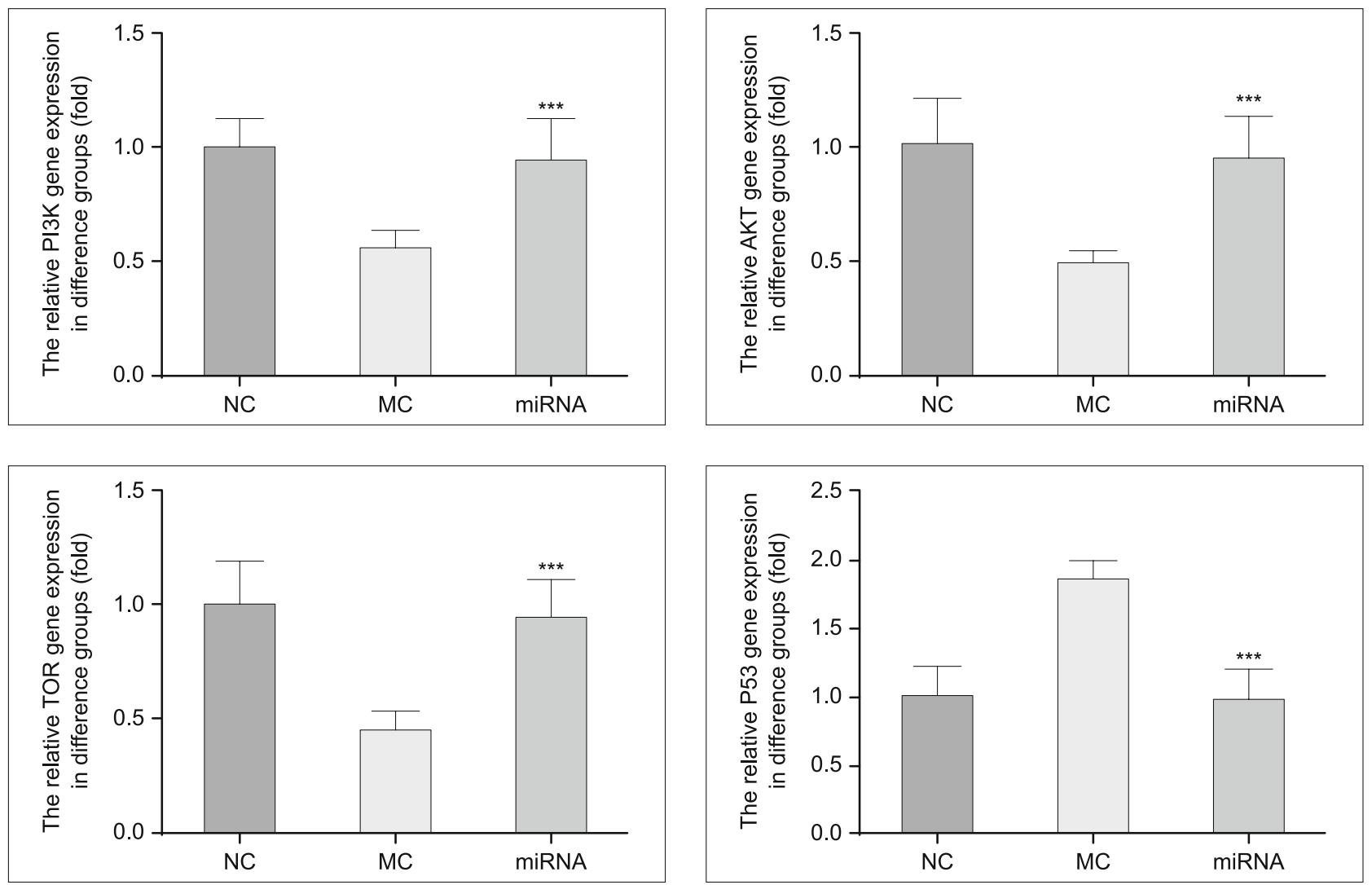

Fig. 4. The relative gene expression of difference groups. ${ }^{* * *}: \mathrm{p}<0.05$, Compared with MC group.
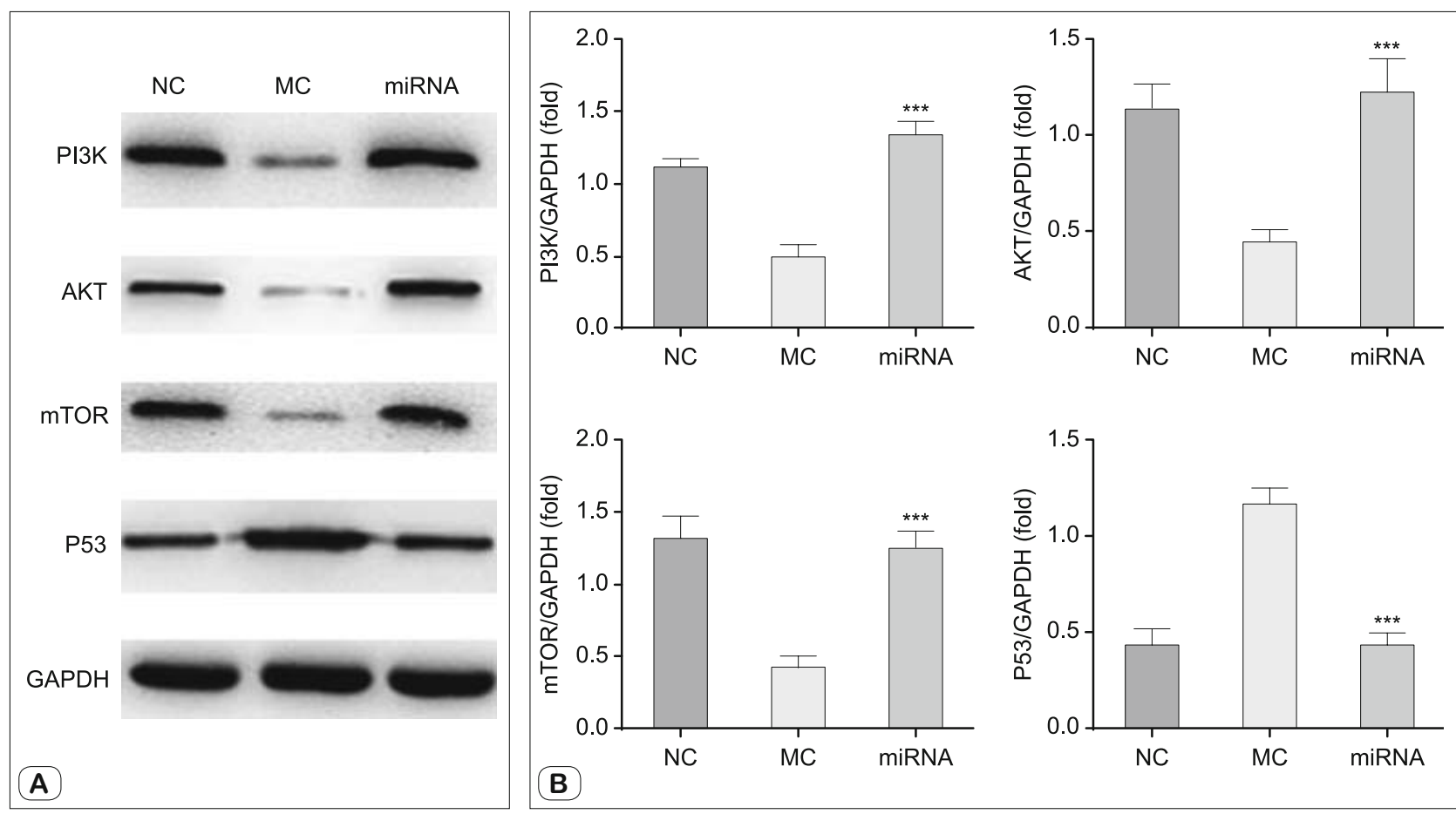

Fig. 5. The relative protein expressions of difference groups. A) The relative proteins expressions by WB assay. B) Comparing the relative protein expressions of difference groups. ***: $\mathrm{p}<0.05$, Compared with MC group. 
that of normal pregnancy. Through the cell experiment, comparing to the MC group, miRNA-145 significantly enhanced cell proliferation rate and effectively reduced the EVCT cell apoptosis rate. In order to further explore its mechanism, we suggested $\mathrm{PI} 3 \mathrm{~K} / \mathrm{Akt} / \mathrm{mTOR}$ signalling pathways as the main factor for testing. The results showed that over-expression miRNA-145 could significantly promote the PI3K/AKT/mTOR signalling pathway and inhibit the P53 expression. We conclude that the low expression of miR-145 and inhibition of PI3K/Akt/mTOR signalling pathway and increased expression of P53 may are the important factors that result in preeclampsia.

\section{Reference}

1. Myatt L. Role of placenta in preeclampsia. Endocrine 2002; 19 (1): 103-111.

2. Fisher SJ. The placental prolem: linking abnormal cytotrophoblast differentiation to the maternal symptoms of preeclampsia. Reprod Biol Endocrinol 2004; 2: 53.

3. Zhou Y, Damsky CH, Chiu K et al. Preeclampsia is associated with abnormal expression of adhesion molecules by invasive cytotrophoblasts. J Clin Invest 1993; 91 (3): 950-960.

4. Gilbert JS, Nijland MJ, Knoblich P. Placental ischemia and cardiovascular dysfunction in preeclampsia and beyond: making the connections. Expert Rev Cardiovasc Ther 2008; 6 (10): 1367-1377.

5. Pringle KG, Kind KL, Sferruzzi-Perri AN et al. Beyond oxygen: complex regulation and activity of hypoxia inducible factors in pregnancy. Hum Reprod Update 2010; 16 (4): 415-431.

6. Sharp AN, Heazell AE, Crocker IP et al. Placental apoptosis in health and disease. Am J Reprod Immunol 2010; 64 (3): 159-169.

7. Murphy MS, Tayade C, Smith GN. Maternal Circulating microRNAs and Preeclampsia: Challenges for Diagnostic Potential. Mol Diagn Ther 2016.

8. Kang MR, Park KH, Yang JO et al. miR-6734 Up-Regulates p21 Gene expression and induces cell cycle arrest and apoptosis in colon cancer cells. PloS one 2016; 11 (8): e0160961.

9. Zhuang Y, Dai J, Wang Y et al. MiR-338 suppresses fibrotic pathogenesis in pulmonary fibrosis through targeting LPA1. Am J Transl Res 2016; 8 (7): 3197-3205.

10. Liu W, Chen X, Zhang Y. Effects of microRNA-21 and microRNA-24 inhibitors on neuronal apoptosis in ischemic stroke (J). Am J Transl Res 2016; 8 (7): 3179-3187.

11. Zhao H, Kang X, Xia $\mathbf{X}$ et al. miR-145 suppresses breast cancer cell migration by targeting FSCN-1 and inhibiting epithelial-mesenchymal transition. Am J Transi Res 2016; 8 (7): 3106-3114.

12. Yui J, Garcia-Lloret M, Wegmann TG et al. Cytotoxicity of tumor necrosis factor-alpha and gamma-interferon against primary human placental trophoblasts (J). Placenta, 1994; 15 (8): 819-835.

13. Crocker IP, Tansinda DM, Baker PN. Altered cell kinetics in cultured placental villous explants in pregnancies complicated by preeclampsia and intrauterine growth restriction. J Pathol 2004; 204 (1): 11-18.

14. Hung TH, Skepper JN, Charnock-Jones DS et al. Hypoxia-reoxygenation: a potent inducer of apoptotic changes in the human placenta and possible etiological factor in preeclampsia. Circ Res 2002; 90 (12): $1274-1281$.
15. Levy R, Smith SD,Chandler K et al. Apoptosis in human cultured trophoblasts is enhanced by hypoxia and diminished by epidermal growth factor (J). Am J Physiol Cell Physiol 2000; 278 (5): C982-988.

16. Heazell AE, Lacey HA, Jones $C J$ et al. Effects of oxygen on cell tumover and expression of regulators of apoptosis in human placental trophoblast (J). Placenta 2008; 29 (2): 175-186.

17. Wang W, Ji G, Xiao X et al. Epigenetically regulated miR-145 suppresses colon cancer invasion and metastasis by targeting LASP1. Oncotarget 2016, doi: 10.18632/oncotarget.11919.

18. Zheng M, Wu Z, Wu A et al. MiR-145 promotes TNF- $\alpha$-induced apoptosis by facilitating the formation of RIP1-FADDcaspase- 8 complex in triple-negative greast cancer. Tumor Biol 2016; 37 (7): 8599-8607.

19. Cui XB, Li S, Li TT et al. targeting oncogenic PLCE1 by miR-145 impairs tumor proliferation and metastasis of esophageal squamous cell carcinoma. Oncotarget 2016; 7 (2): 1777-1795.

20. Karatas OF, Yuceturk B, Suer I et al. Role of miR-145 in human laryngeal squamous cell carcinoma. Head Neck 2016; 38 (2): 260-266.

21. Wang F, Li H, Yan XG et al. Alisertib induceds cell cycle arrest and autophagy and suppress epithelial-to-mesenchymal transition involving $\mathrm{PI} 3 \mathrm{~K} / \mathrm{Akt} / \mathrm{mTOR}$ and sirtuin 1-mediated signaling pathways in human pancreatic cancer cells (J). Drug Des Devel Ther 2015; 17 (9): 575-601.

22. Zhang T, Liang $X$, Shi $\mathbf{L}$ et al. Estrogen Receptor and PI3K/AKT signaling Pathway involvement in S-(-)equol-induced activation of Nrf2/ ARE in endothelial cells. PloS One 2013; 8 (11): e79075.

23. Zhu Y, Pereira Rom, O’Neill BT et al. Cardiac PI3K-Akt impairs insulin-stimulated glucose uptake indepedent of mTORC1 and GLUT4 translocation. Mol Endocrinol 2012; 27 (1): 172-184.

24. Kong XF, Wang XQ, Yin YL et al. Putrescine stimulates the mTOR signaling pathway and protein synthesis in porcine trophectoderm cells. Biol Reprod 2014; 91 (5): 1-10.

25. Mazelin L, Panthu B, Nicot AS et al. mTOR inactivation in myocardium from infant mice rapidly leads to dilated cardiomyopathy due to transtation defects and p53/JNK-mediated apoptosis. J Mol Cell Cardiol 2016; 97: 213-225.

26. Seo BR, Min KJ, Cho IJ et al. Correction: Curcumin Significantly Enhances Dual PI3K/Akt and mTOR Inhibitor NVP-BEZ235-InducedApoptosis in Human Renal Carcinoma Caki Cells through Down-Regulation of p53-Dependent Bcl-2 Expression and Inhibition of Mcl-1 Protein Stability. PloS One 2016; 11 (3): e0151886.

27. Liu QJ, Shen HL, Lin J et al. Synergistic roles of p53 and HIF1 $\alpha$ in human renal cell carcinoma-cell apoptosis responding to the inhibition of mTOR and MDM2 signaling pathways. Drug Des Devel Ther 2016; 10: 745-755.

28. Huang X, Wu Z, Mei Y et al. XIAP inhibits autophagy via XIAPMdm2-p53 signalling. EMBO J 2013; 32 (16): 2204-2216.

29. Nag S, Qin J, Srivenu gopal KS et al. The MDM2-p53 pathway revisited. J Biomed Res 2013; 27 (4): 254-271.

30. Carter BZ, Mak DH, Schober WD et al. Simultaneous activation of p53 and inhibition of XIAP enhance the activation of apoptosis signaling pathways in AML. Blood 2010; 115 (2): 306-314.

Received April 19, 2017. Accepted May 11, 2017. 